\title{
CONJUNTURA HISTÓRICA DE 1848-1851: REELABORAÇÃO DA PRÁTICA E DE TEORIA MARXISTA
}

\author{
COYUNTURA HISTÓRICA DE 1848-1851: REELABORACIÓN DE LA PRÁCTICA Y E LA \\ TEORÍA MARXISTA
}

\author{
HISTORICAL JUNCTURE OF 1848-1851: REVIEW OF THE PRACTICE AND THE \\ MARXIST THEORY
}

Maria de Fátima Rodrigues Pereira ${ }^{1}$

\begin{abstract}
Resumo: Analisa-se neste texto a conjuntura histórica de 1848 a 1851 caracterizada pelas lutas de classes. Para o estudo recorre-se à periodização elaborada por Marx em O 18 de Brumário de Luis Bonapate. Objetiva-se contibuir com outros textos, deste número, da Revista Germinal Marxismo e Educação em Debate, e para o entendimento que o marxismo é uma teoria social e de conhecimento que se elabora a partir da prática dos homens organizados em formações sociais para produzirem o seu existir. O apagamento ou a permanência do marxismo é uma arma para a manutenção ou superação do atual modo de produção da existência caraterizado pela contradição: divisão social do trabalho e apropriação privada dos frutos do trabalho, ao extremo, pela burguesia.
\end{abstract}

Palavras-chave: Conjuntura; Marxismo; Teoria; Prática.

Resumen: Se analiza en este texto la coyuntura histórica de 1848 a 1851 caracterizada por las luchas de clases. Para el estudio se recurre a la periodización elaborada por Marx en O 18 de Brumário de Luis Bonapate. Se objetiva contribuir con otros textos, de este número, de la Revista Germinal Marxismo e Educação em Debate y para la comprensión de que el marxismo es una teoría social y de conocimiento que se elabora a partir de la práctica de los hombres organizados en formaciones sociales para que produzcan su existir. La borradura o la permanencia del marxismo es un arma para la manutención o superación del actual modo de producción de la existencia caracterizado por la contradicción: división social del trabajo y apropiación privada de los frutos del trabajo, al extremo, por la burguesía.

Palabras-1lave: Coyuntura; Marxismo; Teoría; Práctica.

Abstract: In this text the historical juncture of 1848 and 1851, featured by the classes struggles, is analyzed. For this study the time scale elaborated by Marx in "The 18th of Brumaire of Louis Bonaparte" is considered. It is aimed to contribute with other texts, from this edition of the "Germinal Marxismo e Educação em Debate" magazine, and for the understanding that the Marxism is a social and knowledge theory that is elaborated from the practice of the men, organized in social formations to produce their beings. The deletion or the persistence of the Marxism is a weapon to the maintenance or improvement of the current mode of production of the existence characterized by the contradiction: social division of labor and private ownership of the fruits of labor, extremely, by the bourgeoisie.

Key-words: Juncture; Marxism; Theory; Practice.

Hegel faz notar algures, que todos os grandes acontecimentos e personagens históricos ocorrem, por assim dizer, duas vezes. Esqueceu-se de acrescentar: a primeira vez como tragédia, a segunda como farsa. Caussidiére por Danton, Luis Blanc por Robespierre, a Montanha de 1848 a 1851 pela Montanha de 1793 a 1795, o sobrinho pelo tio. Os homens fazem a sua própria história mas não a fazem arbitráriamente, nas condições escolhidas por eles, mas antes sob condições diretamente herdadas e transmitidas pelo passado. A tradição de todas as gerações passadas pesa inexorávelmente sobre a consciência dos vivos. E mesmo quando parecem ocupados em transformar-se, a eles e 
às coisas, em criar algo de absolutamente novo, é precisamente nessas épocas de crise revolucionária que se evocam respeitosamente os espíritos do passado, tomando-lhes de empréstimo os nomes, as palavras de ordem, as roupagens, para surgir no novo palco da história sob esse respeitável disfarce e com essa linguagem emprestada. (MARX, 1975).

Para uma esquerda que vem de longe, os trilhos da Memória são a espinha dorsal da sua identidade. E essa consciência de si é o fulcro de todo o combate emancipatório. Tenhamos, pois, Memória (Fernando Rosas²).

\section{Introdução}

Analisa-se, neste texto, a conjuntura histórica do período comprendido entre 1848 e 1851, com a finalidade de referendar que o marxismo assume a história humana como determinação plena da ontologia e da gnosiologia. Ou seja: afirma a centralidade da própria produção da vida material, do modo como os homens produzem a sua própria existência material, de suas relações de produção e de suas forças produtivas, para se reverem as práticas sociais e o conhecimento a seu respeito.

Efetivamente, o estudo que Marx e Engels fizeram dessa conjuntura possibilitou-lhes compreender o processo em movimento das lutas de classe e a necessidade de reelaborar a própria teoria respeitante a crise, intensidade da crise e revolução.

\section{A conjuntura histórica 1848-1851}

Em O 18 de Brumário de Louis Bonaparte 3 , escrito em 1852, Marx traça três períodos da conjuntura histórica de 1848 a 1851: o primeiro período, compreendido entre 24 de fevereiro (data da queda, em França, do rei Luis Filipe, da casa de Orleans que governava, em nome da burguesia financeira, a França desde 1830) e 4 de maio de 1848, data da reunião da Assembléia Constituinte "e que constituiu o período de fevereiro própriamente dito" (MARX, 1975, p. 21). Conjugou-se neste período uma crise econômica própria ainda do Antigo Regime ligada à dependência da agricultura de subsistência e já uma crise própria do modo da existência capitalista. A crise própria da economia de subsistência advinha das más colheitas de batata, principal alimento popular, em decorrência a fome se instalou, cuja produção tinha sido acometida de uma praga (a praga da batata) desde 1845 e 1846. Já a crise capitalista (excesso de produção) decorria da estagnação do comércio, da indústria e do desemprego entre a classe trabalhadora. $\mathrm{O}$ descontentamento e revolta da burguesia ligada às indústrias e comércio, do campesinato e do proletariado urbano estava instalada e manifestava-se contra a política do ministro de Luis Filipe, Guizot. Em virtude da repressão do governo, a oposição reunia-se em uma série de "banquetes" onde discutia a situação e ações para solucioná-la. O "banquete", comício, de 22 de fevereiro de 1848, contou com a presença em massa de populares. Ali se originou um grande movimento revolucionário com a participação de sociedades secretas, grupos de liberais que se articulavam em jornais em apelo à Guarda Nacional que aderiu à revolta. O rei Luis Filipe, numa tentativa de controlar o processo, demitiu Guizot e seu ministério, política tantas vezes mantidas pelos governos burgueses: mudam-se pessoas para se continuar no mesmo sentido, sob a aparência da mudança. Esta estratégia não surtiu efeito favorável ao governo e 
em 24 de fevereiro o próprio Luis Filipe fugiu. Do movimento oposicionista participavam os partidos: o Legitimista, constituído pela nobreza, deposta em 1830 e desejosa de restaurar a dinastia dos Bourbons; o Bonapartista, constituído por uma pequena burguesia liderada por Luis Bonapate, sobrinho de Napoleão Bonaparte; o Republicano, constituído por liberais, nacionalistas das classes médias, profissionais liberais; e o Socialista, composto por diversas facções que procuravam organizar e representar a classe operária. Com a insurreição e o desfecho da fuga do rei, foi constiuído um governo provisório com representantes das forças sociais presentes no processo revolucionário. Fizeram parte desse governo o poeta Lamartine, representante dos republicanos liberais, a corrente socialista foi representada por Luis Blanc que assumiu a pasta do trabalho. Sob a pressão dos trabalhadores o governo provisório criou as Oficinas Nacionais, espécie de fábricas do Estado destinadas a dar trabalho a numeroso número de trabalhadores. Além desta, os trabalhadores reivindicavam uma república social, direito à greve e diminuição da jornada de trabalho. A finalidade do governo provisório era a eleição de uma Assembleia Constituinte que elaborasse a Constituição da segunda República Francesa (a primeira estendeu-se de 1792 até 1804 quando se deu a coroação de Napoleão Bonaparte como imperador). A Assembléia eleita em abril de 1848 constiui-se com maioria de republicanos liberais, representantes da burguesia industrial, eleitos com votos dos numerosos e conservadores pequenos proprietários rurais. Se o movimento tinha contado com a força revolucionária do proletariado urbano, a Assembleia eleita tornou-se fortemente contrária às propostas revolucionárias.

Ou seja: quando do início deste primeiro período,

[...] com o Povo a erguer as barricadas, a guarda nacional a manter uma atitude passiva, o exército a não opôr qualquer resistência séria e a monarquia a iniciar a sua fuga, a República pareceu impôr-se por si mesma. Cada partido interpretava-se a seu modo. Como fora conquistado pelo proletariado de armas na mão, este imprimiu-lhe sua chancela e proclamou-a República Social. Assim se determinou o conteúdo geral da revolução moderna, conteúdo esse que estava na mais singular contradição como tudo o que podia ser posto imediatamente em prática, dadas a situação e condições concretas, o material existente e o grau de desenvolvimento atingido pelas massas (MARX, 1975, p. 21).

Quando do seu final, "as pretenções dos demais elementos que participaram na revolução de Fevereiro foram reconhecidas pela parte do leão que obtiveram no governo" (MARX, 1975).

Entretanto,

Em nenhum período, portanto, encontramos uma mistura tão variada de frases eloquentes, de insegurança e imperícia, de aspirações mais entusiastas pelo progresso e um domínio mais eficaz da velha rotina, a mais aparente harmonia em toda a sociedade e a discordância mais profunda entre seus elementos. Enquanto o proletariado parisiense se deleitava ainda com as grandiosas perspectivas que se abriam diante de si e se entregava a graves discussões sobre problemas socias, as antigas forças agrupavamse, reuniam-se e encontaravam um apoio inesperado na grande massa da Nação: os camponeses e a pequena burguesia que se precipitaram na cena política logo que as barreiras da monarquia de Julho caíram por terra (MARX, 1975, p. 21).

Com as jornadas de fevereiro a burguesia ligada à indústria e comércio alcançava os seus interesses políticos: 1. a reforma eleitoral, 2. a sua inclusão no governo, derrubando o tradicional domínio absoluto da aristocracia financeira, 3. alargamento do círculo dos privilegiados e 4. o controle das reivindicações e lutas do proletariado urbano. Esse desfecho histórico fez Marx rever a sua concepção de 
Revolução formulada, até então. Engles no Prefácio à obra de Marx Lutas de Classe em França, da edição da revista Die Neue Zeit de 1894-1895 e no livro de Karl Marx Die Lassenkamp in Frankreich 1848 bis 1850, de 1895, apontou que tiveram que rever a teoria sobre a revolução formulada, até então, a partir do processo revolucionário da Revolução Francesa:

Quando a revolução de Fevereiro rebentou, todos nós, no respeitante às representações das condições e do curso dos movimentos revolucionários, nos encontrávamos sob o fascínio da experiência histórica anterior, nomeadamente da França. E era precisamente desta experiência, que tinha dominado toda a história europeia desde 1789, que de novo partia o sinal para a revolução geral. Era, portanto, óbvio e inevitável que as nossas ideias sobre a natureza e o curso da revolução "social" proclamada em Paris em Fevereiro de 1848, a revolução do proletariado, estivessem fortemente tingidas pelas recordações dos modelos de 1789-1830 (ENGLES, 2009).

Esta nova conjutura histórica possibilitava entender e expressar que: 1. as contradições que determinavam o movimento histórico de 1848 iniciavam a luta entre a burguesia e proletariado, que passava a ser, conforme Marx, o conteúdo geral da revolução moderna; 2. que o movimento da revolução não é linear, no processo houve recomposição, pelo alto, das frações da burguesia, o que fazia rever a estratégia da luta da classe operária, a própria concepção de revolução e portanto da História:

E, finalmente, quando o levantamento de Paris encontrou o seu eco nas sublevações vitoriosas de Viena, Milão e Berlim; quando toda a Europa até à fronteira russa era arrastada para o movimento: quando em junho se travou em Paris a primeira grande batalha pela dominação entre o proletaraido e a burguesia; quando a própria vitória da sua classe abalou de tal modo a burguesia de todos os países que ela voltou a refugiar-se nos braços da reação monárquica-feudal que acabava de ser derrubada - não podia haver para nós qualquer dúvida, dadas as circuntâncias de então (ENGLES, 2009).

Esta recomposição no seio da burguesia exigiu rever a prática, impunha repensar a estratégia revolucionária do proletariado, que apesar da grande luta decisiva ter começado, ainda "tinha de ser travada num único período revolucionário longo e cheio de vicissitudes, mas que só podia terminar com a vitória definitiva do proletariado" (ENGLES, 2009, p. 5). Rever a teoria à luz da história, impunha reelaborar em pensamento os princípios (os pontos de vista) da própria prática histórica "Porém, a história não nos deu razão e demonstrou que os nossos pontos de vista dessa altura eram uma ilusão. E ainda mais além: não só destruiu nosso erro de então como revolucionou totalmente as condições em que o proletariado tem que lutar" (ENGLES, 2009, p. 5).

O segundo período comprende o processo ocorrido entre 4 de maio de 1848 até o fim de maio de 1849, que corresponde à reorganização das facções da burguesia com visats à constituição da república burguesa que substituía a monarquia burguesa. Ou seja: enquanto que, sob a monarquia era uma minoria restrita da burguesia que havia governado em nome do rei, agora, era o conjunto da burguesia que governava em nome do povo. Os conflitos, no início de maio entre a burguesia e os trabalhadores se agudizaram. O operariado parisiense, sem trabalho, tomou as ruas, o resultado do confronto foi favorável à burguesia, o afastamento de Blanqui significou afastar do governo provisório da Assembleia, os comunistas e socialistas. A resposta do Proletariado veio com as insurreições de junho. Neste confronto também, 
A República burguesa levou a melhor. Ela tinha ao seu lado a aristocracia financeira, a burguesia industrial, as classes médias, a pequena burguesia, o exército, o lumpenproletariad organizado em guarda móvel, os intelectuais, os padres e toda a população rural. O proletariado não contava com mais ninguém, a não ser com ele próprio. Mais de 3.000 revoltosos foram sacrificados após a vitória e 15.000 deportados sem julgamento. Esta derrota atirou o proletariado para o último plano da cena revolucionária (MARX, 1975, p. 23).

O ataque ao operariado intensificou-se com o fechamento das Oficinas Nacionais. Da soma das alianças do operariado resultaram derrotas sucessivas. Seus principais representantes na Assembleia e na Imprensa, atacados, "caíram uns atrás dos outros, vítimas dos tribunais e substituídos por personalidades cada vez mais equívocas"( MARX, 1975, p. 23). Aliado com a burguesia para o enfrentamento da monarquia burguesa, o proletariado viu-se traído pela república igualmente burguesa. A derrota do proletariado foi ao mesmo tempo a vitória da burguesia e possibilidade da revolução do proletariado que passava a ser tão certa quanto aquela da burguesia. Em 22 de junho, novo levante proletário ameaçou o poder controlado pela burguesia, o revide foi do aparelho de Estado constituído pela Guarda Móvel composta por representantes da pequena burguesia, do campesinato, do lumpen-operariado, do exército nacional sob o comando de Cavaignac sob o estado de sítio. Com a eleição para a presidência da República, convocada pela Assembleia em decorrência do que rezava a Constituição Republicana elaborada sob a proteção das baionetas de Cavaignac, ocorrida em 10 dezembro de 1848, elegeu-se Luis Bonaparte com $73 \%$ dos votos. A facção republicana-burguesa alçada ao poder por um levantamento do proletariado contra o capital, por sua vez sofucado a tiros da canhão, via seu reinado interrompido com a vitória das forças sociais congregadas por Luis Napoleão. Sobrinho de Napoleão Bonaparte (o outro candidato tinha sido o próprio Cavaignac), Luis Bonaparte organizou, durante o ano de 1848, o Partido da Ordem composto por diversas facções políticas, conservadoras, sob uma propaganda e promessas de glórias e riquezas semelhantes às da época do Império Napoleônico.

Passados 5 meses, em maio de 1849, foram realizadas eleições para a Assembleia Legislativa. Estas consagraram o retorno dos monarquistas, com uma vitória que resultou na presença de 450 deputados de um total de 750. Este foi o desfecho do segundo período que se constitui sobre a derrota do proletariado.

O terceiro período da conjuntura histórica que estamos analisando, para que não se perca a memória e a compreensão dos estudos e da prática emancipatória, comprende o período entre maio de 1849 a dezembro de 1851. Caracterizam-no, inicialmente, os conflitos entre os interesses representados na Assembleia e o governo de Bonaparte.

Por um lado 750 representantes do povo, eleitos por sufrágio universal e reelegíveis, constituindo uma Assembleia Nacional irresponsável, indissolúvel, indivisível, uma Assembléia Nacional desfrutando de uma omnipotência legislativa, decidindo em última instância em questões de guerra, paz e tratados de comércio, possuindo sozinha o direito à amnistia, e, pelo seu caráter permanente, ocupando sempre o primeiro lugar da cena. E do outro lado, o Presidente, com todos os seus poderes do poder real, com o direito de nomear e exonerar os seus ministros independentemente da Assembléia Nacional, tendo na mão todos os meios do poder executivo, dispondo de todos os postos, e dispondo assim em França da existência de pelo menos um milhão e meio de 
pessoas, pois tal é número dos que dependem dos 50.000 funcionários e autoridades de todas as categorias (MARX, 1975, p. 32).

A rejeição da Assembleia ao projeto do governo de Emenda Constitucional de reeleição para a Presidência da República serviu de pretexto para, após dezessete meses de traições e disputas entre o governo e a Assembleia, Luis Napoleão fechar a Assembleia. Apoiado pela sociedade Dez de Dezembro, composta por um lumpen-operariado com o objetivo de reprimir qualquer manifestação operária e pelo exército, o sobrinho, repetindo o gesto histórico de seu tio, dissolveu a Assembleia e proclamou-se presidente por 10 anos em 2 de dezembro de 1851, 18 de Brumário pelo calendário elaborado durante o governo da Convenção.

A partir desta conjuntura histórica Marx reelaborou a prática e teoria marxista. Efetivamente, o estudo deste período que constitui a obra de Marx - Lutas de Classe em França 1848-1851 elaborado com o método da concepção materialista e dialética da história, possibilitou a Marx e a Engels rever suas concepções de revolução e de estratégia da luta do proletariado:

A nós e a todos quantos pensávamos de modo semelhante a história não deu razão. Mostrou claramente que nessa altura o nível do desenvolviemnto económico de modo algum estava amadurecido para a eliminação da produção capitalista. Demonstrou isto por meio da revolução econômica que alastrava por todo o continente desde 1848 e fizera a grande indústria ganhar pela primeira vez foros de cidadania em França, na Áustria, na Hungria, na Polônia e ultimamente na Rússia, e, além disso tornara a Alemanha num país industrial de primeira categoria. E tudo isto sobre fundamentos capitalistas que, em 1848, ainda tinham grande capacidade de expansão. Mas foi precisamente esta revolução industrial que, pela primeira vez, por toda a parte, trouxe luz às relações entre as classes. Foi ela que eliminou uma quantidade de formas intermédias que provinham do período manufatureiro e, na Europa Oriental, mesmo do artesanato corporativo, e que criou uma verdadeira burguesia e um verdadeiro proletariado da grande indústria ao mesmo tempo que os fazia passar ao primeiro plano do desenvolvimento social (ENGELS, 2009).

De 1851 a 1871 foram somente 20 anos caracterizados pela expansão da industrialização, disputa entre o capital e luta entre este e a classe trabalhadora. Em 1870, a capitulação da França em Sedan perante o exército Alemão foi o estopim para o recrudeceder das lutas e durante 72 dias (a partir de 18 de março de 1871), Paris foi governada sob os interesses da democracia mais autêntica da história da humanidade, o governo dos comunardos. A burguesia respondeu ao ímpeto revolucionário com as armas, o sangue e a deportação. A comuna de Paris foi a demonstração da possiblidade de uma cidadania ativa, direta e emancipatória.

\section{Referências:}

ENGELS, F. Introdução à edição de 1895. In: MARX, K. As lutas de classes em França de 1848 a 1851. Disponível em: <http:www.Marxists.org/portugueses/marx/1850/11/lutas_class/introdução.htm>. Acesso em: 10 maio 2009.

MARX, K. O 18 de Brumário de Luis Bonaparte. Coimbra: Centelha, 1975.

\section{Notas}


${ }^{1}$ Doutora em Educação pela Universidade Estadual de Campinas. Professora do Programa do Mestrado em Educação da Universidade Tuiuti do Paraná. Email: pereiramfatima@hotmail.com

2 Ver artigo publicado neste número da Revista Germinal.

3 O texto: O 18 de Brumário de Luis Bonaparte foi escrito inicialmente, por Marx, entre janeiro e fevereiro de 1851, para ser publicado por seu amigo Joseph Weydemeyer em Nova York. Vicissitudes fizeram com que só viesse a lume no primeiro número da revista mensal do mesmo Joseph Weydemeyer ainda em 1952. O título que Marx atribuiu ao Golpe de Estado de Luis Bonaparte desferido em 2 de dezembro de 1851 foi usado para remeter o sobrinho ao gesto do tio que em 9 de novembro de 1799 (18 pelo calendário da Convenção, a república francesa jacobina) apoiado pelos banqueiros, também deu o Golpe de Estado, promovendo-se juntamente com dois membros do Diretório - o abade Siéyes e Roger Ducos - à condição de consul, emitando nesse gesto o Triunvirato Romano que também desembocou no império como com Napoleão Bonaparte (em 1804) e seu sobrinho Luis Bonaparte (um ano depois do Golpe, em dezembro de 1852). 